\title{
Envolvimento de Aeromonas em surto de doença diarréica aguda em São Bento do Una, Pernambuco
}

\author{
Aeromonas associated with an acute diarrhea outbreak \\ in São Bento do Una, Pernambuco
}

\author{
Ernesto Hofer ${ }^{1}$, Cristhiane Moura Falavina dos Reis ${ }^{1}$, Grace Nazareth Diogo Theophilo ${ }^{1}$, \\ Valdelúcia Oliveira Cavalcanti², Nancy Veloso de Lima² e \\ Maria de Fátima Correia de Miranda Henriques ${ }^{3}$
}

\begin{abstract}
RESUMO
No primeiro semestre de 2004, ocorreu um surto de diarréia em São Bento do Una, Pernambuco, registrando-se 2.170 casos. Nas 582 coproculturas realizadas, 145 (25\%) revelaram um enteropatógeno bacteriano, destacando 114 casos (19,5\%) com a participação de Aeromonas, representadas por Aeromonas caviae (57/9,8\%), Aeromonas veronii biovar sobria (23/3,9\%), Aeromonas veronii biovar veronii $(15 / 2,6 \%)$ e outras espécies (19/3,2\%). Nos 31 episódios restantes (5,3\%), foram detectados: V. cholerae $O_{1}$ Ogawa toxigênico (18/3,1\%), Salmonella spp $(8 / 1,4 \%)$, Shigella $\operatorname{spp}(3 / 0,5 \%)$ e Vibrio cholerae não $O_{1} /$ não $O_{139}(2 / 0,3 \%)$.
\end{abstract}

Palavras-chaves: Surto. Diarréia aguda. Aeromonas.

\begin{abstract}
An acute diarrhea outbreak, with 2170 cases, was described during January to July, 2004, in São Bento do Una, Pernambuco. 582 stools were examined and an enteric pathogen was recovered in 25\% (145 patients). Aeromonas species were the most frequent (114-19.5\%) and the main isolates were Aeromonas caviae (57-9.8\%), Aeromonas veronii biovar sobria (23-3.9\%), Aeromonas veronii biovar veronii (15-2.6\%) and other species (19-3.2\%). The other isolated enteropathogens were Vibrio cholerae $O_{1}-$ Ogawa toxigenic (18-3.1\%), Salmonella $\operatorname{spp}$ (8-1.4\%), Shigella $\operatorname{spp}(3-0.5 \%)$ and Vibrio cholerae non-O $/$ non- $_{139}(2-0.3 \%)$.
\end{abstract}

Key-words: Outbreak. Acute diarrhea. Aeromonas.

0 ponto de alerta que suscitou o problema, resultou no isolamento e identificação em abril de 2004 de uma amostra de Vibrio cholerae $\mathrm{O}_{1}$ sorovar Ogawa pelo Laboratório Central de Saúde Pública do Estado de Pernambuco, a partir de uma coprocultura de paciente com diarréia, residente em São Bento do Una. Em consequiência, as investigações epidemiológicas instituídas no local pela Secretaria de Saúde do Estado (SSE) e Secretaria de Vigilância em Saúde (SVS) do Ministério da Saúde, reconheceram que a população do município estava sendo assolada por um surto de doença diarréica aguda com início no final de janeiro e reproduzindo o mesmo acontecimento do ano anterior (2003) segundo os dados da Secretaria de Saúde do Estado (Figura 1), embora não tenham sido registrados laboratorialmente casos de cólera desde 2001 no estado.
0 município de São Bento do Una, situa-se na região agreste do estado, distando $215 \mathrm{~km}$ da capital, com uma população de 46.626 habitantes e tendo como atividade econômica preponderante a avicultura. As condições de saneamento básico são precárias, em vista do fornecimento de água potável à população ser escasso e intermitente, obrigando os consumidores recorrer à água colhida em barreiros (pequenos açudes) além daquela distribuída por veículos carros-pipa particulares, todas sem controle microbiológico. 0 esgotamento sanitário de um modo geral apresenta extravasamento do conteúdo para o meio ambiente (valas a céu-aberto) nos bairros fora do perímetro urbano e, via de regra, as águas residuais não tratadas são lançadas diretamente no rio Una, que banha a cidade.

\footnotetext{
1. Departamento de Bacteriologia do Instituto Oswaldo Cruz da Fundação Oswaldo Cruz, Rio de Janeiro, RJ. 2. Laboratório Central de Saúde Pública Dr. Milton Bezerra Sobral, Recife, PE. 3. Secretaria de Saúde do Estado de Pernambuco, Recife, PE.

Endereço para correspondência: Dr. Ernesto Hofer. Lab. Zoonoses Bacterianas/Dept ${ }^{\circ}$ de Bacteriologia/IOC/FIOCRUZ. Av. Brasil 4365, Manguinhos, 21040-900 Rio de Janeiro, RJ.

Tel: 5521 2598-4277 r.332, Fax: 21 2270-6565

e-mail: hofer@uninet.com.br

Recebido para publicação em 13/5/2005

Aceito em 23/12/2005
} 


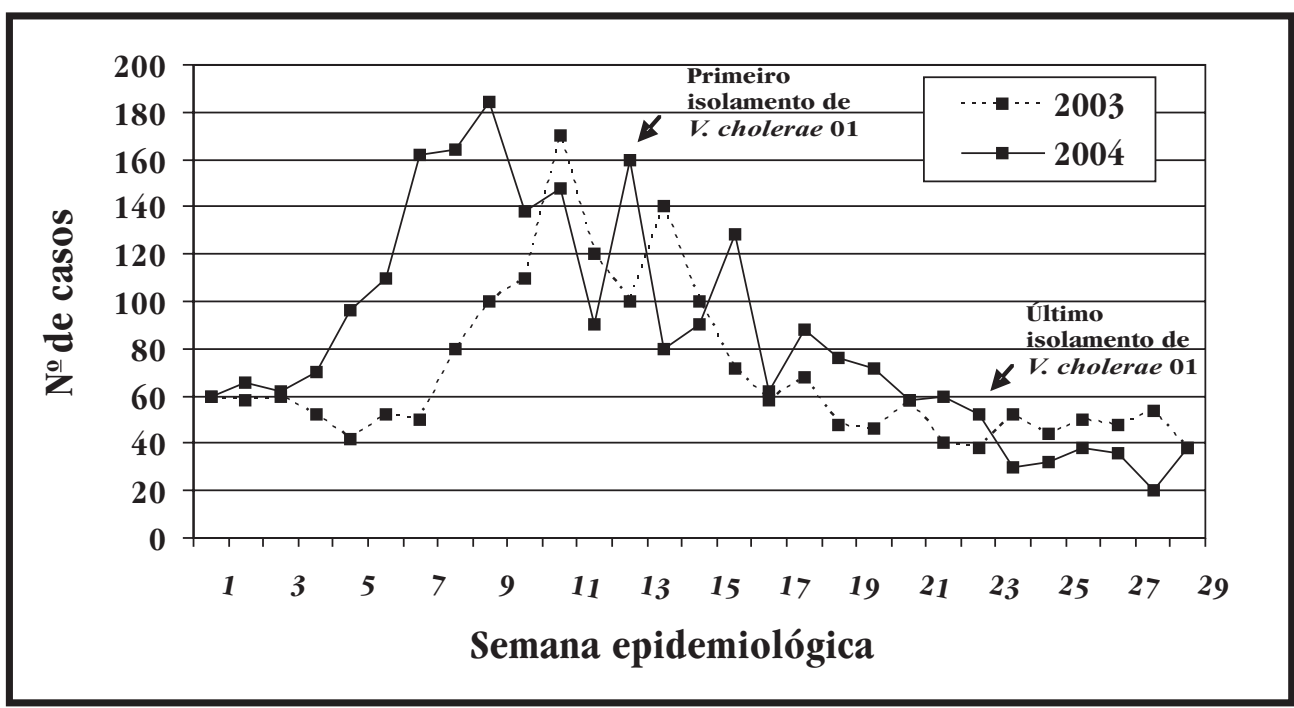

Figura 1 - Casos de diarréia aguda por semana epidemiológica (1 a 29), São Bento do Una, Pernambuco, 2003 e 2004. (Fonte: SSE-PE)

Com a detecção do vibrião colérico uma das medidas adotadas consistiu na coleta sistemática de amostras clínicas dos casos suspeitos de diarréia (morador apresentando síndromes coleriforme ou disenteriforme, com mais de duas evacuações por dia). As fezes colhidas por swab fecal ou retal, mantidas em meio de transporte de Cary \& Blair foram prontamente encaminhadas ao Laboratório Central (LACEN), Recife. Assim, no período de abril até junho foram analisadas 582 amostras de fezes, incluindo dos familiares de comunicantes e de 30 espécimes de um grupo controle (morador do município, sem problemas intestinais na fase do surto).

Tanto nos Laboratórios, Central de Saúde Pública do Estado como no de Referência Nacional de Cólera e outras Enteroinfecções Bacterianas, Instituto Oswaldo Cruz/FIOCRUZ/ $\mathrm{RJ}$, foram adotados os esquemas clássicos ${ }^{23410}$ para o isolamento e identificação fenotípica dos membros das famílias Enterobacteriaceae, Vibrionaceae e Aeromonadaceae. Na pesquisa de genes associados à virulência de $V$. cholerae $0_{1}$ foi utilizada a metodologia preconizada por Keaster \& Hall ${ }^{5}$ com pequenas modificações?.
A investigação epidemiológica registrou 2.170 casos de diarréia no período de janeiro a início de julho, sendo que 1.146 $(52,8 \%)$ ocorreram entre 20 de março e 30 de junho, época em que se efetuou a coleta de fezes.

$\mathrm{Na}$ característica da diarréia, predominou a síndrome coleriforme, isto é, emissão de fezes aquosas com três a quatro episódios por dia, geralmente acompanhado de vômito, náusea e cólicas abdominais, embora outros sinais foram registrados como a febre e desidratação. Talvez, a presença desses vários sinais clínicos, estivesse relacionada à situação inusitada dos achados bacteriológicos, com a incidência não fortuita, mas predominante de isolamentos de Aeromonas na população analisada (114 casos-19,5\%) quando confrontada com os $31(5,3 \%)$ casos com as etiologias clássicas ( $V$. cholerae $0_{1}$, Salmonella, Shigella, incluindo $V$. cholerae não $O_{1} /$ não $O_{139}$ ).

Os resultados bacteriológicos foram associados aos grupos etários portadores (Tabelas 1 e 2), onde se verificou que os isolamentos de $V$. cholerae $0_{1}$ Ogawa predominaram nos pacientes masculinos (11-61\%), enquanto a detecção de Aeromonas spp prevaleceu no sexo feminino (54-59,3\%).

Tabela 1 - Freqüência de enteropatógenos bacterianos isolados de um surto de diarréia aguda (São Bento do Una) e distribuídos por grupos etários.

\begin{tabular}{|c|c|c|c|c|c|c|c|}
\hline \multirow[b]{2}{*}{ Faixa etária } & \multirow[b]{2}{*}{ Aeromonas } & \multicolumn{2}{|c|}{ Vibrio cholerae } & \multirow[b]{2}{*}{ Salmonella } & \multicolumn{2}{|c|}{ Shigella } & \multirow[b]{2}{*}{ Tota } \\
\hline & & $O_{1}$ & não $O_{I} / O_{139}$ & & flexneri & sonnei & \\
\hline $0-11 \mathrm{~m}$ & 16 & - & - & $1^{*}$ & & & 17 \\
\hline $1-5 a$ & 39 & 8 & 1 & $2^{* *}$ & & & 50 \\
\hline $6-10$ & 5 & 1 & & & & & 6 \\
\hline $11-19$ & 10 & 3 & 1 & $2 * * * *$ & & & 16 \\
\hline $20-29$ & 9 & 2 & & $1^{* * * * *}$ & & & 12 \\
\hline $30-39$ & 11 & 3 & & & 1 & 1 & 16 \\
\hline $40-49$ & 8 & & & & & & 8 \\
\hline $50-59$ & 9 & & & & & 1 & 10 \\
\hline $60-69$ & 1 & & & $1 * * * * *$ & & 0 & 2 \\
\hline$>70$ & 6 & 1 & & $1^{* * * * *}$ & & & 8 \\
\hline Total & 114 & 18 & 2 & 8 & 1 & 2 & 145 \\
\hline
\end{tabular}


Tabela 2 - Freqüência das espécies do gênero Aeromonas isoladas de um surto de diarréia aguda (São Bento do Una) e distribuídas por grupos etários.

\begin{tabular}{|c|c|c|c|c|c|c|c|c|c|c|}
\hline \multirow[b]{3}{*}{ Faixa etária } & \multicolumn{9}{|c|}{ Aeromonas } & \multirow{3}{*}{ Total } \\
\hline & caviae & veronii & veronii & media & jandaei & hydrophila & schubertii & trota & $\mathrm{sp}$ & \\
\hline & & bio*. sobria & bio*. veronii & & & & & & & \\
\hline $0-11 \mathrm{~m}$ & 9 & 2 & 1 & 3 & 1 & & & & & 16 \\
\hline $1-5 a$ & 23 & 4 & 5 & 3 & & 1 & & & 3 & 39 \\
\hline $6-10$ & 1 & 2 & 1 & 1 & & & & & & 5 \\
\hline $11-19$ & 5 & 2 & - & - & - & - & 1 & 1 & 1 & 10 \\
\hline $20-29$ & 4 & 2 & 2 & - & 1 & & & & & 9 \\
\hline $30-39$ & 3 & 5 & 3 & - & & & & & & 11 \\
\hline $40-49$ & 6 & 2 & - & - & & & & & & 8 \\
\hline $50-59$ & 4 & 2 & 1 & 1 & 1 & & & & & 9 \\
\hline $60-69$ & 1 & - & - & - & & & & & & 1 \\
\hline$>70$ & 1 & 2 & 2 & - & & 1 & & & & 6 \\
\hline Total & 57 & 23 & 15 & 8 & 3 & 2 & 1 & 1 & 4 & 114 \\
\hline
\end{tabular}

Em ambas as situações, a faixa etária mais comprometida situou-se em 1 a 5 anos (50-34,4\%), tendo em seqüência os grupos de 0 a 11 meses (17-11,7\%), 11 a 19 anos e 30 a 39 anos, cada um com 16 (11\%) pessoas. Da maioria dos grupos etários foram isolados membros do gênero Aeromonas, em especial $A$. caviae (57-9,8\%), A. veronii biovar sobria (23-3,9\%) e A. veronii biovar veronii (15-3,2\%) que, por sinal, são as espécies mais freqüentemente relacionadas com doenças humanas ${ }^{4}$.

Outro aspecto interessante do surto, foi a multiplicidade de enteropatógenos bacterianos isolados, embora só se tenha tido uma associação (A. caviae + Salmonella infantis), contrariando a expectativa da participação múltipla de agentes por indivíduo. As condições precárias de saneamento básico e as limitações dos preceitos de higiene pessoal e do ambiente domiciliar, favoreciam tal hipótese, além da projeção da diarréia no grupo de 0 a 5 anos, que é mais suscetível as infecções entéricas com associação de agentes $^{78}$. Provavelmente, caso as pesquisas de Escherichia coli, em particular, enterotóxica e enteropatogênica e de Campylobacter termofílicos fossem encetadas na ocasião, alguma associação de etiologias poderia ser reconhecida ${ }^{78}$. Por outro lado, a investigação de entidades virais, resultou em negativa.

Salienta-se que as espécies de Aeromonas estão amplamente distribuídas em natureza, principalmente nos ecossistemas aquáticos ${ }^{1}$, envolvendo animais pecilotérmicos e aquelas com características mesofílicas podem causar diversas infecções no homem $^{4612}$. Em diferentes partes do mundo a sua incidência nas doenças entéricas varia de 1 a $27 \%$, inclusive como causa freqüente da diarréia do viajante, além de apresentar a figura de portador assintomático em crianças e adultos ${ }^{12}$. Todavia, a questão de reconhecer Aeromonas spp como enteropatógeno não tem a unanimidade entre os especialistas, embora algumas espécies são capazes de produzir vários fatores de virulência, como hemolisinas, enterotoxinas ou citotoxinas ${ }^{11}$.

King e cols ${ }^{6}$ demonstraram que a casuística das infecções entéricas por Aeromonas era similar a de Campylobacter e tomando por base como causa de doença diarréica as seguintes circunstâncias: 1) Predominância acentuada de casos sintomáticos sobre os assintomáticos; 2) Ausência de outros enteropatógenos, bacteriano ou viral nos pacientes com diarréia aguda; 3 ) Melhora do quadro clínico após antibioticoterapia ou manutenção dos sintomas, no caso de Aeromonas resistente aos antimicrobianos; 4) Resposta imune anti-Aeromonas na secreção intestinal de pacientes que foram acometidos de infecção entérica por Aeromonas.

Diante dos resultados obtidos, e considerando os aspectos clínico-epidemiológicos arrolados, dirime-se a dúvida da participação de certas espécies de Aeromonas no presente acontecimento, que mimetizaram e se compatibilizaram com a síndrome relatada para $V$. cholerae $0_{1} /$ toxigênico, além de ter apresentado a forma epidêmica, circunstância raramente descrita na literatura.

\section{AGRADECIMENTOS}

À população de São Bento do Una. Aos Drs. Ana Maria de Lima Barros (LACEN/PE), Zuleide Dantas Vanderley e Guilherme José Robalinho de Oliveira (Secretaria de Saúde do Estado, PE) pelo incentivo e apoio. Aos técnicos de laboratório do LACEN/PE: Rosa Maria Palmeira Cordeiro de Melo, Maria Josefa de Almeida e do Instituto Oswaldo Cruz, RJ, Darcília Maria de Andrade.

\section{REFERÊNCIAS BIBLIOGRÁFICAS}

1. Araújo RM, Pares R, Lucena F. The effect of terrestrial effluents on the incidence of Aeromonas spp in coastal waters. Journal of Applied Bacteriology 69:439-444, 1990.

2. Costa GA, Hofer E. Isolamento e identificação de enterobactérias. Monografia, Instituto Oswaldo Cruz, Rio de Janeiro, RJ, 1972.

3. Hofer E. Métodos utilizados para o isolamento e identificação de Vibrio cholerae. Informe de Patologia Clínica 1: 5-18, 1975.

4. Janda JM, Abbott SL. Evolving concepts regarding the genus Aeromonas: an expanding panorama of species, disease presentations, and unanswered questions. Clinical Infectious Diseases 27:332-344, 1998. 
5. Keasler SP, Hall RH. Detecting and biotyping of Vibrio cholerae 0 with multiplex polymerase chain reaction. Lancet 341: 1661-1664, 1993.

6. King GE, Werner SB, Kizer KW. Epidemiology of Aeromonas infection in California. Clinical Infectious Diseases 15:449-452, 1992.

7. Lacerda MD, Pontes JDC, Hofer E. Circulação de enterobactérias patogênicas em menores institucionalizados. II. Estudo bacteriológico. Revista de Microbiologia, São Paulo, 19:135-140, 1988.

8. Leal NC, Cavalcanti TIR, Silva MIB, Reis EMF, Solari CA, Hofer E. Freqüência de enterobactérias patogênicas em processos diarréicos infantis na cidade do Recife, Pernambuco. Memórias do Instituto Oswaldo Cruz 83: 475-479, 1998.
9. Leal NC, Sobreira M, Leal-Balbino TC, Almeida AMP, Silva MJB, Mello DM, Seki LM, Hofer E. Evaluation of a RAPD-based typing scheme in molecular epidemiology study of Vibrio cholerae $0_{1}$, Brazil. Journal of Applied Microbiology 96:447-454, 2004.

10. Ministério da Saúde. Comissão Nacional de Prevenção do Cólera. Cólera: Manual de diagnóstico laboratorial. Brasília, 1992.

11. Thornley JP, Shaw JG, Gryllos IA, Eley A. Virulence properties of clinically significant Aeromonas species: evidence for pathogenicity. Review of Medical Microbiology 8:61-72, 1997.

12. Yamada S, Matsushita S, Dejsirilert S, Kudoh Y. Incidence and clinical symptoms of Aeromonas-associated travellers diarrhoea in Tokyo. Epidemiology and Infection 119:121-126, 1997. 